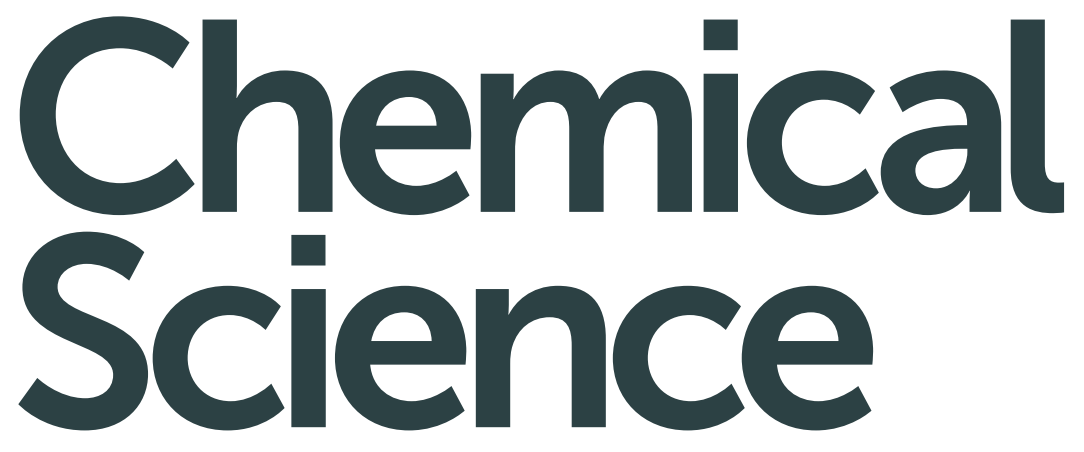

rsc.li/chemical-science

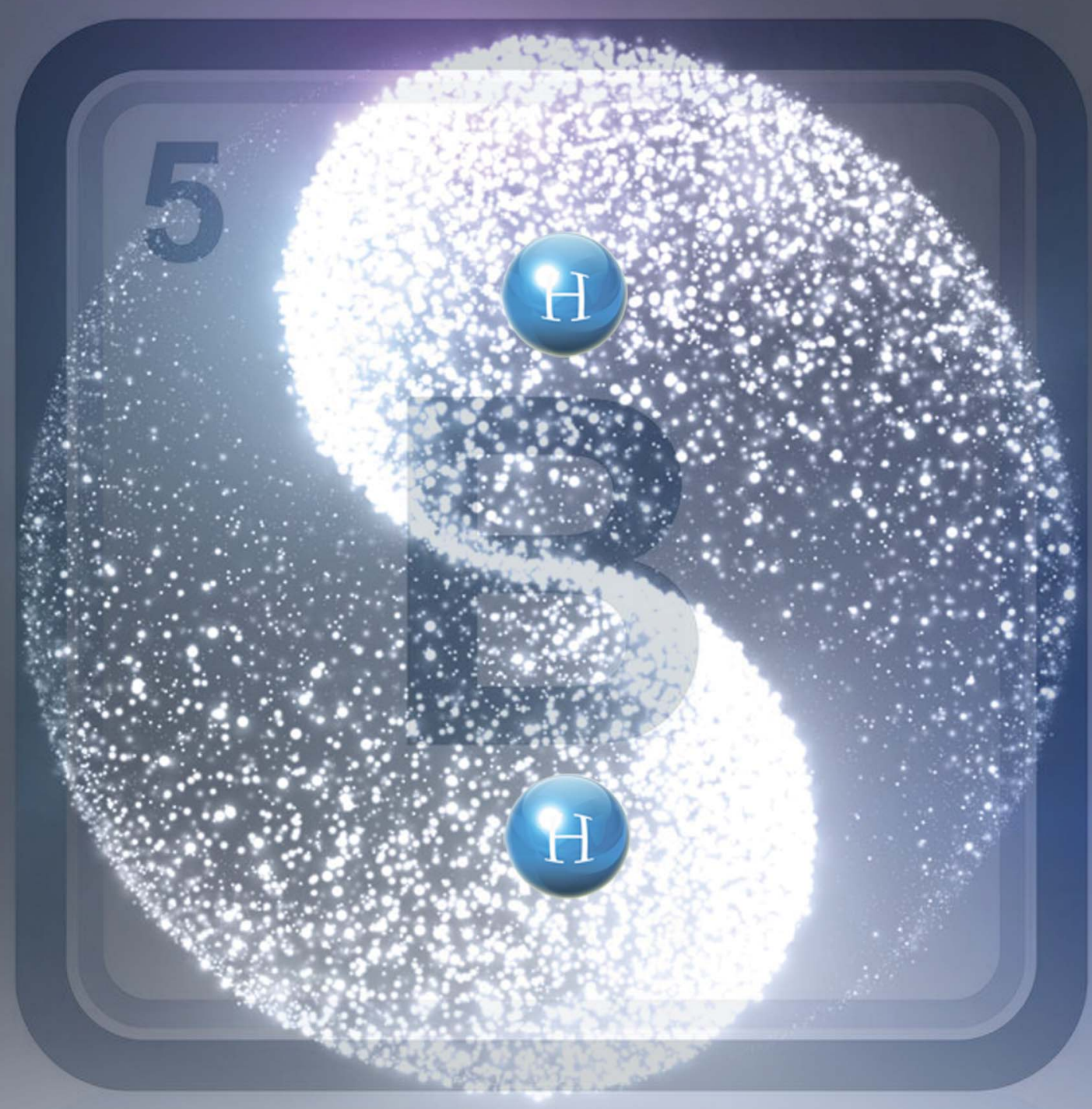

ISSN 2041-6539

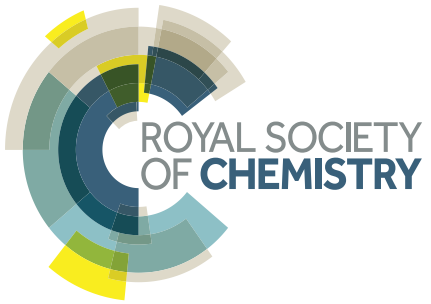


Check for updates

Cite this: Chem. Sci., 2018, 9, 1433

Received 21st November 2017 Accepted 27th November 2017

DOI: $10.1039 / \mathrm{c} 7 \mathrm{sc} 04987 \mathrm{k}$

rsc.li/chemical-science

\section{Addition of dihydrogen to a borylborenium center $\dagger$}

\begin{abstract}
Junhao Zheng, Zhen Hua Li (D) * and Huadong Wang (D) *
The activation of $\mathrm{a} \mathrm{H}-\mathrm{H}$ bond, the simplest covalent bond, is a fundamentally important process. Addition of $\mathrm{H}_{2}$ to an elemental center typically occurs on low valent transition metal or main group complexes through oxidative addition to afford metal dihydride complexes. In contrast, activation of $\mathrm{H}_{2}$ on a high valent center generally results in heterolytic cleavage of the $\mathrm{H}-\mathrm{H}$ bond to a proton and hydride. Here, we report experimental and computational evidence for the addition of $\mathrm{H}_{2}$ to a borenium center in an $\mathrm{N}$ heterocyclic carbene $(\mathrm{NHC})$ coordinated borylborenium cation, which leads to the formation of a dihydroborenium complex accompanied by the elimination of two $\sigma$-bonded substituents, namely mesityl (Mes) and pinacolboryl (Bpin) groups, as mesitylboronic ester.
\end{abstract}

\section{Introduction}

The activation of dihydrogen is a key step for hydrogenation reactions, which are considered as "the largest-volume humanmade chemical reactions in the world". ${ }^{1,2}$ In the activation process, the $\mathrm{H}-\mathrm{H} \sigma$ bonding orbital is depopulated along with population of the $\mathrm{H}-\mathrm{H} \sigma^{*}$ anti-bonding orbital. Possessing empty/filled d orbitals suitable for interaction with $\mathrm{H}_{2}$ orbitals, low valent transition metal complexes can activate $\mathrm{H}-\mathrm{H}$ bonds through oxidative addition, affording metal-dihydride complexes (Scheme 1a). ${ }^{1}$ Such oxidative addition is not limited to transition metal complexes. Low valent main group complexes, such as carbenes, ${ }^{3}$ silylenes ${ }^{4}$ and $\mathrm{Al}(\mathrm{I})^{5}$ complexes, can also activate $\mathrm{H}_{2}$ through oxidative addition due to the presence of an empty $\mathrm{p}$ orbital and a lone pair on the central element which can synergistically interact with $\mathrm{H}_{2}$ orbitals. On the other hand, high valent transition metal or main group complexes cannot undergo oxidative addition when treated with $\mathrm{H}_{2}$ due to their lack of filled d orbitals or lone pairs. Instead, they can activate $\mathrm{H}_{2}$ through either $\sigma$ bond metathesis or base-assisted activation (Scheme $1 \mathrm{~b}$ and $\mathrm{c}$ ). The former pathway mainly involves $\mathrm{d}^{0}$ or $\mathrm{d}^{0} \mathrm{f}^{n}$ metal complexes, resulting in hydrogenolysis of one $\mathrm{M}-\mathrm{E} \sigma$ bond and the formation of a hydride species and $\mathrm{H}-\mathrm{E}$ compound. ${ }^{6}$ The latter pathway includes synergistic interaction of a Lewis acid and base with $\mathrm{H}_{2}$, exemplified by the well-studied Noyori catalysts ${ }^{7}$ and the recently emerging frustrated Lewis pairs (FLPs), ${ }^{8}$ which leads to the formation of a hydride species and a protonated base. In contrast, the addition of $\mathrm{H}_{2}$ to a high valent element center to

Department of Chemistry, Shanghai Key Laboratory of Molecular Catalysis and Innovative Materials, Fudan University, Handan Road 220, Shanghai, 200433, China.E-mail: huadongwang@fudan.edu.cn; lizhenhua@fudan.edu.cn

$\dagger$ Electronic supplementary information (ESI) available. CCDC 1543216 (4). For ESI and crystallographic data in CIF or other electronic format see DOI: 10.1039/c7sc04987k afford dihydride species still remains unknown (Scheme 1d). ${ }^{9}$ Such a reaction pathway would involve the cleavage of three $\sigma$ bonds with the concomitant formation of three new ones.

Recently, we ${ }^{\mathbf{1 0}}$ and the group of Nikonov ${ }^{\mathbf{1 1}}$ independently discovered that electrophilic hydroboranes can activate $\mathrm{H}_{2}$ in the absence of Lewis bases through $\sigma$ bond metathesis at $60^{\circ} \mathrm{C}$. Miqueu, Bouhadir and Bourissou et al. reported that phosphine coordinated mesityborenium complexes can react with $\mathrm{H}_{2}$ at $80{ }^{\circ} \mathrm{C}$ to afford corresponding hydroborenium complexes and mesitylene. ${ }^{12,13}$ Our theoretical investigation suggests that the charge transfer from the bonding orbital of a B-E bond to the $\sigma^{*}$ anti-bonding orbital of $\mathrm{H}_{2}$ plays an important role in the $\mathrm{H}_{2}$ activation process. ${ }^{14}$ To increase the reactivity of organoboranes

a) oxidative addition

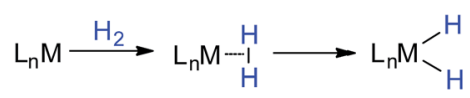

b) $\sigma$ bond metathesis

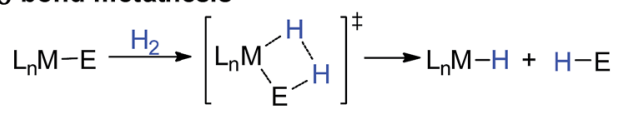

c) base assisted activation

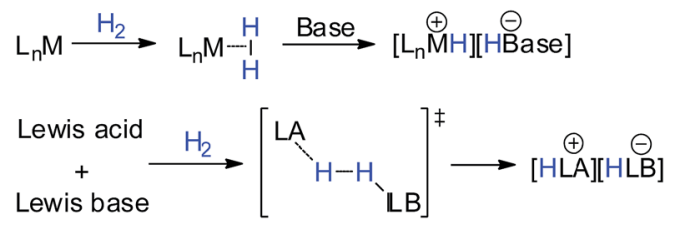

d) concurrent addition/elimination (this work)

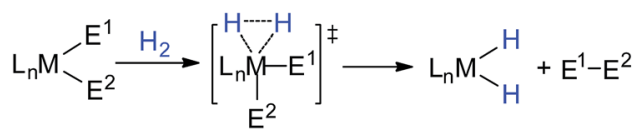

Scheme 1 Mechanisms for the activation of $\mathrm{H}_{2}$ 
against $\mathrm{H}_{2}$, we synthesized an $\mathrm{N}$-heterocyclic carbene (NHC) coordinated borylborenium cation (1), ${ }^{\mathbf{1 5}, 16}$ anticipating that the boryl substituent would enhance the interaction between the B-B bonding orbital and the $\sigma^{*}$ anti-bonding orbital of $\mathrm{H}_{2}$. Indeed, borenium 1 was found to be able to activate $\mathrm{H}_{2}$ at a temperature as low as $-40{ }^{\circ} \mathrm{C}$. Additionally, to our surprise, the borenium center was inserted into the $\mathrm{H}-\mathrm{H}$ bond, affording a dihydroborenium complex. Herein we report the synthesis of borenium 1 and its reactivity against $\mathrm{H}_{2}$ along with experimental and theoretical investigation of the reaction mechanism.

\section{Results and discussion}

\section{Synthesis of 1 and its reactivity against $\mathrm{H}_{2}$}

To prepare the precursor for borenium 1, $\mathrm{IMe}_{4}$ borane derivative $\mathrm{IMe}_{4}-\mathrm{B}(\mathrm{H})_{2} \mathrm{Mes}\left(2, \mathrm{IMe}_{4}=1,3,4,5\right.$-tetramethylimidazol-2ylidene) was treated with $\mathrm{I}_{2}{ }^{17}$ to afford $\mathrm{IMe}_{4}-\mathrm{B}(\mathrm{H})(\mathrm{I}) \mathrm{Mes}$, which was not isolated but directly reacted with IPrCuBpin (IPr = 1,3-bis(2,6-diisopropylphenyl)imidazol-2-ylidene, Bpin = pinacolboryl), ${ }^{18}$ producing the unsymmetrical diboron complex 3 in $52 \%$ yield (Scheme 2 ). The ${ }^{11} \mathrm{~B}$ NMR spectrum of 3 features one singlet at $40.9 \mathrm{ppm}$ and one doublet at $-29.5 \mathrm{ppm}$ with the former assigned to the Bpin unit and the latter to the NHC coordinated $\mathrm{BH}$ moiety. Hydride abstraction from 3 with one equivalent of $\left[\mathrm{Ph}_{3} \mathrm{C}\right]\left[\mathrm{B}\left(\mathrm{C}_{6} \mathrm{~F}_{5}\right)_{4}\right]$ in toluene at $25{ }^{\circ} \mathrm{C}$ resulted in near quantitative formation of the borylborenium complex $\mathbf{1}$. After purification, complex 1 could be isolated in $96 \%$ yield and was characterized using NMR spectroscopy, high resolution mass spectrometry (HRMS) and elemental analysis. In the ${ }^{11} \mathrm{~B}$ NMR spectrum of $\mathbf{1}$, the resonance corresponding to the NHC coordinated boron atom appears at $78.0 \mathrm{ppm}$ as a broad singlet, which is consistent with the formation of a borenium cation. ${ }^{\mathbf{1 5}}$ An upfield shift of the Bpin moiety (32.8 ppm) compared to 3 was also observed. The identity of $\mathbf{1}$ was further confirmed using derivatization. Treatment of 1 with one equivalent of 4-dimethylaminopyridine (DMAP) gave DMAP coordinated boronium complex 4, which was characterized using X-ray diffraction.

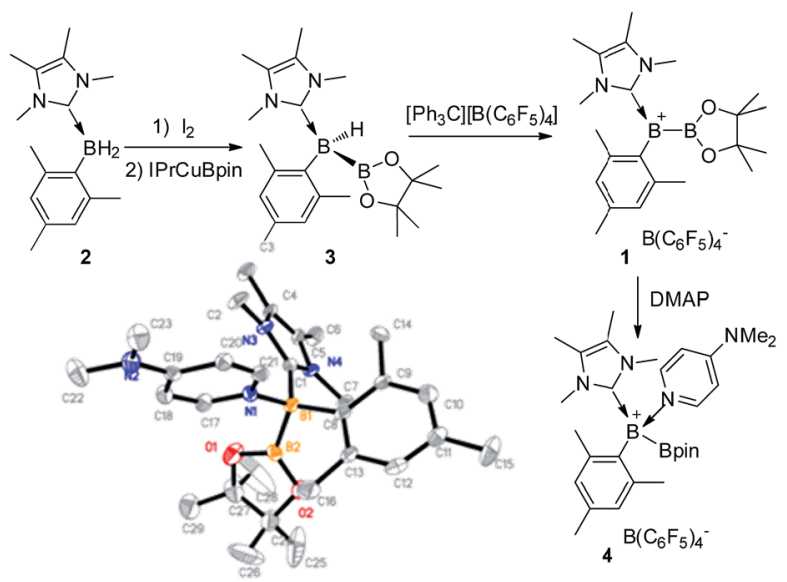

Scheme 2 Synthesis of 1 and 4 , and the molecular structure of 4 (the hydrogen atoms and counter anion $\mathrm{B}_{(}\left(\mathrm{C}_{6} \mathrm{~F}_{5}\right)_{4}{ }^{-}$are omitted for clarity).
When the amount of DMAP was increased to two equivalents, complex 4 was still the only observable product and no bisDMAP adduct was produced.

When treated with 1.5 bar $\mathrm{H}_{2}$ in a toluene solution at room temperature, borenium 1 was quantitatively converted to a new species 5 in less than one minute. This reaction can take place at a much lower temperature. Stirring of the solution of $\mathbf{1}$ under 4.0 bar $\mathrm{H}_{2}$ for 2 hours at $-40{ }^{\circ} \mathrm{C}$ also resulted in the quantitative formation of 5 (Scheme 3). This represents the mildest conditions for the activation of $\mathrm{H}_{2}$ by an organoboron species. ${ }^{\mathbf{1 9 , 2 0}}$ Although complex 5 decomposes to unidentified complexes in bromobenzene solution after 1 day at room temperature, it was fully characterized using NMR and HRMS analysis. In the ${ }^{1} \mathrm{H}$ NMR spectrum of 5, a broad signal at $\delta 2.87$ ppm was observed, which was assigned to a $\mathrm{BH}_{2}$ moiety after comparison with the corresponding ${ }^{1} \mathrm{H}\left\{{ }^{11} \mathrm{~B}\right\}$ NMR spectrum. We also noticed that the signal for the pinacol moiety appears as a broad singlet at $\delta 1.26 \mathrm{ppm}$, which prompted us to carry out a VT-NMR study (Fig. 1). At $60{ }^{\circ} \mathrm{C}$, the signal for the pinacol moiety appears as a sharp singlet at $\delta 1.30 \mathrm{ppm}$. Upon cooling to $-20{ }^{\circ} \mathrm{C}$, this signal decoalesces to two broad singlets ( $\delta 1.39$ and $1.12 \mathrm{ppm})$, implying the existence of inequivalent methyl groups in the pinacol moiety. The signals corresponding to the Mes moiety also become broad during the cooling process, and those for $\mathrm{IMe}_{4}$ are largely temperature-invariant. In the ${ }^{11} \mathrm{~B}$ NMR spectrum of 5 at $25{ }^{\circ} \mathrm{C}$, besides the signal from the anion $\left[\mathrm{B}\left(\mathrm{C}_{6} \mathrm{~F}_{5}\right)_{4}\right]^{-}$ at $\delta-15.9 \mathrm{ppm}$, two broad singlets at $\delta 33.3$ and $-7.6 \mathrm{ppm}$ were observed. As the former is in the range of a tricoordinate boron and the latter indicates the formation of a tetracoordinate boron, we assigned compound 5 as the adduct of $\left[\mathrm{IMe}_{4} \mathrm{BH}_{2}\right]$ $\left[\mathrm{B}\left(\mathrm{C}_{6} \mathrm{~F}_{5}\right)_{4}\right]$ and MesBpin with the oxygen atom of the pinacol moiety coordinating to the boron center of $\left[\mathrm{IMe}_{4} \mathrm{BH}_{2}\right]^{+}$. A similar coordinate mode was observed in a Bi(III) complex in which the Bi(III) center is coordinated by the oxygen atom of a borate ester moiety. ${ }^{21}$ In agreement with this assignment, HRMS analysis of $\mathbf{5}$ revealed the formation of fragments $\left[\mathrm{IMe}_{4} \mathrm{BH}_{2}\right]^{+}$and $[\mathrm{MesBpinLi}]^{+}$(Li ion was added as an ionization source). Our assignment was further confirmed by the independent synthesis of compound 5 from the borenium salt $\left[\mathrm{IMe}_{4} \mathrm{BH}_{2}\right]\left[\mathrm{B}\left(\mathrm{C}_{6} \mathrm{~F}_{5}\right)_{4}\right]^{22}$ and MesBpin, which shows identical NMR spectra. The MesBpin moiety in $\mathbf{5}$ is readily replaced by a stronger base such as DMAP, affording the literature known boronium salt $\left[\mathrm{IMe}_{4} \mathrm{~B}(\mathrm{H})_{2}(\mathrm{DMAP})\right]\left[\mathrm{B}\left(\mathrm{C}_{6} \mathrm{~F}_{5}\right)_{4}\right]^{22}$ and free MesBpin. Treatment of 1 with $D_{2}$ resulted in the formation of the corresponding deuterated analog $\mathbf{5}-\mathbf{D}_{\mathbf{2}}$. The ${ }^{2} \mathrm{H}$ NMR spectrum
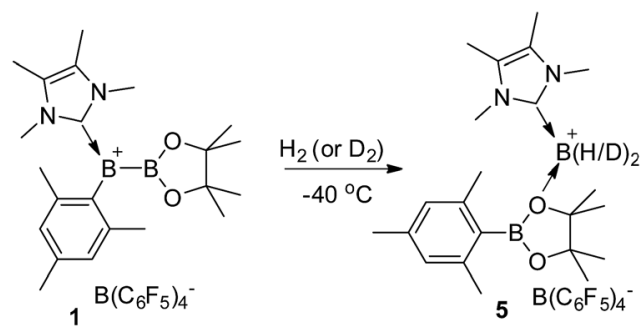

Scheme 3 Reaction of borylborenium 1 with $\mathrm{H}_{2}$ or $\mathrm{D}_{2}$. 


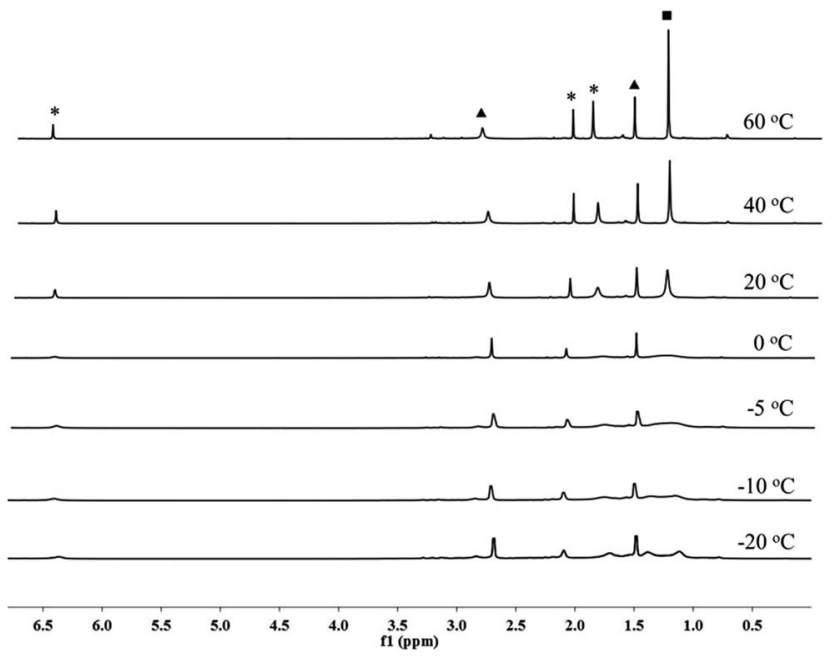

Fig. 1 VT-NMR spectra of 5 in $C_{6} D_{5} B r$

: Bpin, $\mathbf{\Lambda}: \mid \mathrm{Me}_{4}, *$ : Mes).

of 5- $\mathbf{D}_{2}$ displays a broad resonance at $\delta 2.86 \mathrm{ppm}$ originating from the $\mathrm{BD}_{2}$ moiety. ${ }^{23}$ After quenching with DMAP, [IMe ${ }_{4}^{-}$ $\left.\mathrm{B}(\mathrm{D})_{2}(\mathrm{DMAP})\right]\left[\mathrm{B}\left(\mathrm{C}_{6} \mathrm{~F}_{5}\right)_{4}\right]$ and MesBpin were obtained, confirming that the two hydride substituents in $\mathbf{5}$ originate from $\mathrm{H}_{2}$. To the best of our knowledge, this is the first time that the insertion of a boron center to a $\mathrm{H}-\mathrm{H}$ bond has been observed. ${ }^{24}$ In a related study, Stephan and Bertrand reported that an acyclic(alkyl)(amino)carbene supported borylene can undergo a 1,2addition reaction when treated with $\mathrm{H}_{2}$ and a dihydroboron species was proposed as a transient intermediate from the oxidative addition of $\mathrm{H}_{2}$ on the boron center. ${ }^{25}$ Recently, the groups of Wagner ${ }^{26}$ and Yamashita ${ }^{27}$ discovered that diboron species, such as reduced 9,10-dihydro-9,10-diboraanthracene and $(o-\mathrm{Tol})_{2} \mathrm{BB}(o-\mathrm{Tol})_{2}$, can function as FLPs to react with $\mathrm{H}_{2}$, affording hydroborane complexes.

\section{Experimental mechanism studies}

To probe the reaction mechanism, we carried out a kinetic study of the reaction between 1 and $\mathrm{H}_{2}$ which was monitored using ${ }^{1} \mathrm{H}$ NMR spectroscopy. Besides the starting material $\mathbf{1}, \mathrm{H}_{2}$ and the final product $\mathbf{5}$, no intermediate was observed in the reaction mixture. The rate of disappearance of 1 under a 10 -fold excess of $\mathrm{H}_{2}$ followed pseudo-first-order kinetics. A linear dependence of the observed rate constant $k_{\text {obs }}$ on the $\mathrm{H}_{2}$ pressure at $-15{ }^{\circ} \mathrm{C}$ suggested a first-order dependence on $\mathrm{H}_{2}$ pressure. These data were consistent with an overall second-order rate law for the $\mathrm{H}_{2}$ activation reaction. Kinetic measurements at temperatures ranging from -45 to $-5{ }^{\circ} \mathrm{C}$ allow the determination of activation parameters $\left(\Delta H^{\neq}=6.2(2) \mathrm{kcal} \mathrm{mol}^{-1}\right.$ and $\Delta S^{\neq}=-33.8(6)$ cal $\mathrm{mol}^{-1} \mathrm{~K}^{-1}$ ) (Fig. 2a). The low value of $\Delta S^{\neq}$implies an associative mechanism. Furthermore, an inverse kinetic isotope effect $(\mathrm{KIE}=0.80)$ was obtained by measuring the rate constant of the reaction between 1 and $D_{2}$ (Fig. 2b), which indicates the existence of a dihydrogen complex in a rapid equilibrium before the $\mathrm{H}-\mathrm{H}$ bond is cleaved. ${ }^{1}$ Observations of inverse KIEs for $\mathrm{H}_{2}$ activation reactions are rare. We only noticed two examples in the literature, which involve $\operatorname{Ir}^{28}$ and $\mathrm{Fe}^{29}$ complexes.
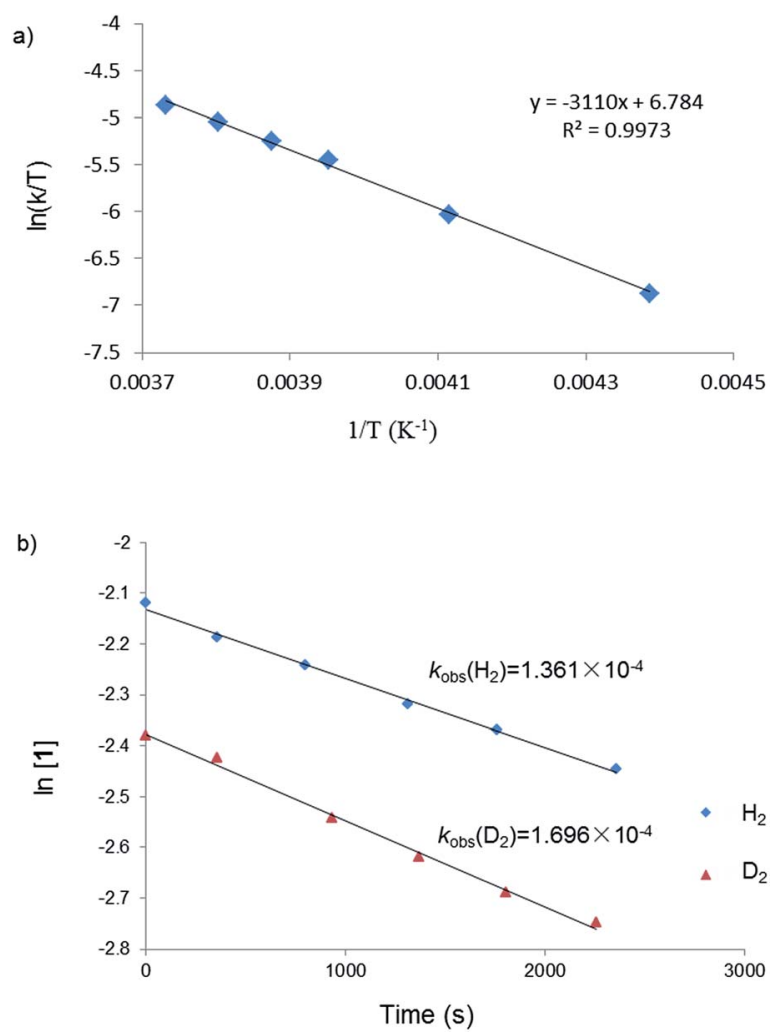

Fig. 2 (a) Eyring plot of the reaction between 1 and $\mathrm{H}_{2}$; (b) plots of the reactions between 1 and $\mathrm{H}_{2}$ or $\mathrm{D}_{2}$ at $258 \mathrm{~K}$.

Based on the kinetic study, three possible mechanisms could be considered for the formation of complex 5 from borenium 1 and $\mathrm{H}_{2}$. One mechanism (Scheme 4, path $\mathrm{I}$ ) is that borenium 1 undergoes reductive elimination to afford borinylium intermediate 6 , followed by the oxidative addition of $\mathrm{H}_{2}$ and coordination of MesBpin to form complex 5. The second proposed mechanism (Scheme 4, path II) involves the initial formation of $\left[\mathrm{IMe}_{4} \mathrm{~B}(\mathrm{H}) \mathrm{Mes}\right]\left[\mathrm{B}\left(\mathrm{C}_{6} \mathrm{~F}_{5}\right)_{4}\right](7)$ and HBpin, ${ }^{26}$ which subsequently go through ligand exchange to form complex 5. A third mechanism (Scheme 4, path III) would be that the addition of $\mathrm{H}_{2}$ and

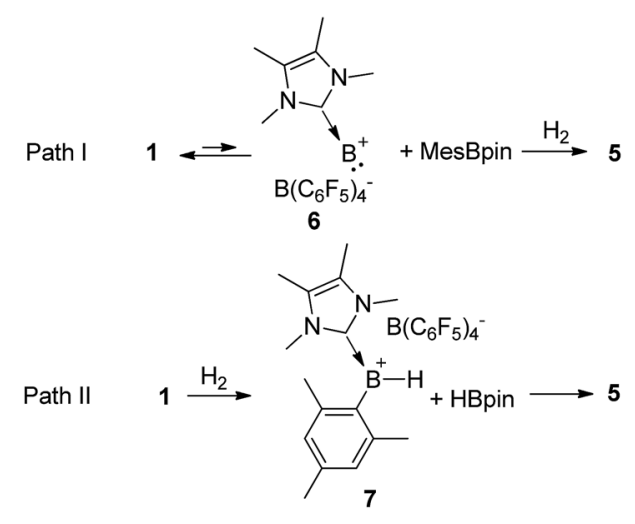

Path III $\quad 1 \stackrel{\mathrm{H}_{2}}{\longrightarrow} 5$

Scheme 4 Possible reaction pathways for the formation of complex 5. 
elimination of MesBpin occur in a concomitant manner. Both of the latter two pathways could proceed via initial coordination of $\mathrm{H}_{2}$ to the borenium center of $\mathbf{1}$.

If path $\mathrm{I}$ is operative, the reductive elimination and the reverse reaction, oxidative addition, must be very facile. To test this hypothesis, we mixed equimolar amounts of borenium 1 and (Mes- $\left.d_{9}\right)\left(\right.$ Bpin- $\left.d_{12}\right)$ in toluene and no H/D scrambling was observed even at $80{ }^{\circ} \mathrm{C}$. Therefore, path I can be ruled out. To test the feasibility of path II, we synthesized borenium 7 and studied its reactivity against HBpin. Mixing equimolar amounts of 7 and HBpin at room temperature led to the quantitative formation of $\mathbf{5}$ in one minute. When this reaction took place at $-78{ }^{\circ} \mathrm{C}$, complete conversion to 5 was observed after $10 \mathrm{~min}$. No adduct of 7 and HBpin was observed while monitoring this reaction at $-78{ }^{\circ} \mathrm{C}$ using ${ }^{11} \mathrm{~B}$ NMR spectroscopy (Fig. S45 $\dagger$ ). Subsequent kinetic study revealed that the activation parameters $\Delta H^{\neq}$and $\Delta S^{\neq}$for this reaction are 2.5(1) $\mathrm{kcal} \mathrm{mol}^{-1}$ and -44.9 (3) cal $\mathrm{mol}^{-1} \mathrm{~K}^{-1}$, respectively.

To distinguish paths II and III, we examined the reaction of an equimolar mixture of $\mathbf{1}$ and the deuterated analog [ $\mathrm{IMe}_{4}$ $\mathrm{B}\left(\right.$ Bpin- $\left.d_{12}\right)\left(\right.$ Mes- $\left.\left.d_{9}\right)\right]\left[\mathrm{B}\left(\mathrm{C}_{6} \mathrm{~F}_{5}\right)_{4}\right](\mathbf{1 - D})$ with $\mathrm{H}_{2}$ in toluene (no H/D scrambling was observed for this mixture before $\mathrm{H}_{2}$ was introduced). If path II is effective, one would anticipate the observation of the non-crossover products (MesBpin and (Mes$\left.d_{9}\right)\left(\right.$ Bpin- $\left.d_{12}\right)$ ) and crossover products (Mes(Bpin- $\left.d_{12}\right)$ and (Mes$d_{9}$ Bpin) in a $1: 1$ ratio after quenching with DMAP, as the solvent cage effect should only play an insignificant role in the second step in path II due to the comparatively high free-energy barrier of this step. Alternatively, path III would lead to the observation of only the non-crossover products, as the H/D scrambling of complex 5 and its deuterium analog $\left[\mathrm{IMe}_{4}\right.$ $\mathrm{B}(\mathrm{H})_{2}\left(\left(\right.\right.$ Mes- $\left.d_{9}\right)\left(\right.$ Bpin- $\left.\left.\left.d_{12}\right)\right)\right]\left[\mathrm{B}\left(\mathrm{C}_{6} \mathrm{~F}_{5}\right)_{4}\right]$ was found to be much slower (less than $1 \%$ crossover product was observed after stirring for $30 \mathrm{~min}$ at room temperature).

Intriguingly, the observed ratios of non-crossover to crossover products imply that this reaction could proceed through both paths II and III with the latter favored at lower temperature (Table 1). When this reaction is conducted at $-78{ }^{\circ} \mathrm{C}$, the ratio of non-crossover to crossover products is $90: 10$.

Increasing the reaction temperature to $10{ }^{\circ} \mathrm{C}$ resulted in a decrease in the ratio to $73: 27$. Using the ratio of non-crossover to crossover products, we can estimate the ratio of the rate constants for path II and III, $k_{\mathrm{II}} / k_{\mathrm{III}}$ (for calculation details see ESI $\dagger$ ), and thus approximate $\Delta \Delta H^{\neq}$and $\Delta \Delta S^{\neq}$, which are

Table 1 The ratio of rate constants for path II and path III $\left(k_{\|} / k_{\| I I}\right)$ at various temperatures

\begin{tabular}{llll}
\hline & & $\begin{array}{l}\text { Non-crossover }: \text { crossover } \\
\text { products }\end{array}$ & \\
Entry & Temp. $(\mathrm{K})$ & $k_{\mathrm{II}} / k_{\mathrm{III}}$ \\
\hline 1 & 195 & $90: 10$ & 0.24 \\
2 & 213 & $87: 13$ & 0.36 \\
3 & 233 & $82: 18$ & 0.54 \\
4 & 253 & $80: 20$ & 0.69 \\
5 & 273 & $76: 24$ & 0.91 \\
6 & 283 & $73: 27$ & 1.18
\end{tabular}

estimated to be 1.9(1) $\mathrm{kcal} \mathrm{mol}^{-1}$ and 6.9(4) $\mathrm{cal} \mathrm{mol}^{-1} \mathrm{~K}^{-1}$, respectively. However, from the experimental data, we cannot tell whether this activation parameter difference corresponds to the rate-determining step (RDS) or a product-determining step after the RDS.

\section{Theoretical studies}

To further understand the reaction mechanism, the free-energy profile of this reaction was computed using density functional theory (DFT) calculations (M06-2X) (Fig. 3). ${ }^{30}$ First, $\mathrm{H}_{2}$ coordinates to the borenium center (B1) of $\mathbf{1}$ to form a dihydrogen complex $\mathbf{1} \cdot \mathbf{H}_{\mathbf{2}}$ through transition state TS1, in which the $\mathrm{H}-\mathrm{H}$ bond is slightly activated and elongated from 0.737 to $0.817 \AA$. Subsequently, $\mathrm{H}_{2}$ is cleaved to form an intermediate IM1 through transition state TS2, which is the rate-limiting step. TS2 is $15.6 \mathrm{kcal} \mathrm{mol}^{-1}$ greater than free $\mathbf{1}$ and $\mathrm{H}_{2}$ in free energy, which is comparable to the experimental value of $16.3 \mathrm{kcal} \mathrm{mol}^{-1}$. In TS2, the $\mathrm{H}-\mathrm{H}$ bond is substantially weakened and elongated to 1.040 $\mathrm{A}$. Both $\mathrm{H}$ atoms are closely bonded to the B1 atom with $\mathrm{B} 1-\mathrm{H} 1$ and $\mathrm{B} 1-\mathrm{H} 2$ bond distances of 1.269 and $1.244 \AA$, respectively. Unlike the four-centered transition state for $\sigma$ bond metathesis, ${ }^{6}$ only a very weak interaction between B2 and the $\mathrm{H} 2$ atom (1.729 $\AA$ ) is observed, which corresponds to a bond order of 0.11 according to natural bond orbital (NBO) analysis. The B1-B2 bond in TS2 is significantly weakened as well, and its distance is increased from $1.708 \AA$ in 1 to $1.761 \AA$. In IM1, the $\mathrm{H}-\mathrm{H}$ bond is completely cleaved. Concomitantly, a B1-H1 bond is observed with a bond length of $1.192 \AA$. The $\mathrm{H} 2$ atom forms a highly unsymmetrical threecenter two-electron (3c2e) bond with B1 and B2, and the B1$\mathrm{H} 2$ and $\mathrm{B} 2-\mathrm{H} 2$ bond distances are 1.245 and $1.469 \AA$, respectively. Interestingly, the ipso carbon atom of the mesityl moiety also forms a B-C-B 3c2e bond with B1 and B2, and the B1-C1 and B2-C1 bond distances are 1.708 and $1.765 \AA$, respectively. As a result, IM1 can be considered as an adduct of borenium $\left[\mathrm{IMe}_{4} \mathrm{BH}_{2}\right]^{+}$and MesBpin linked with two 3c2e bonds. ${ }^{31}$ IM1 can

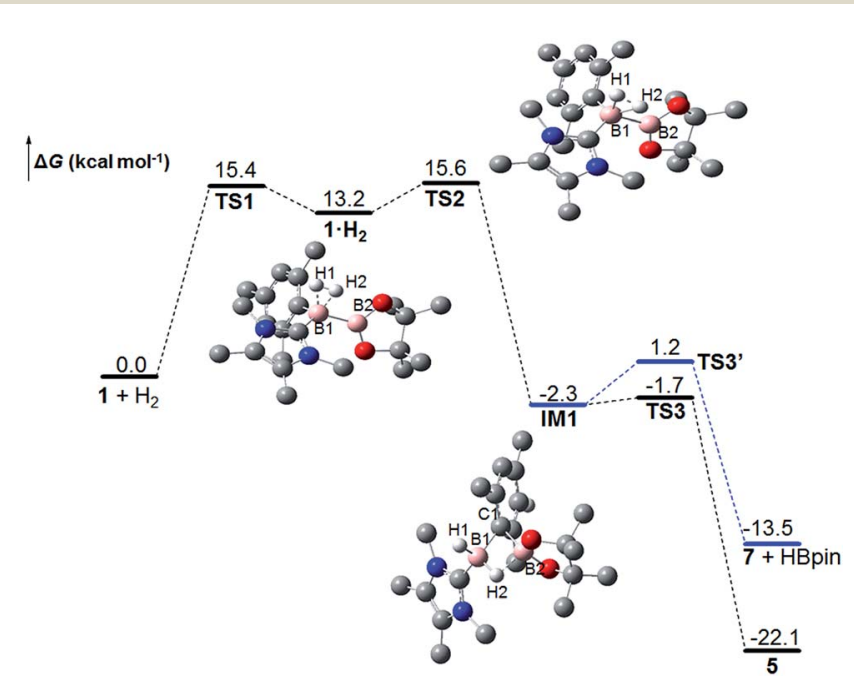

Fig. 3 The Gibbs free energy profile at $298 \mathrm{~K}$ for the reaction between 1 and $\mathrm{H}_{2}$ ( $\mathrm{H}$ atoms (except $\mathrm{H} 1$ and $\mathrm{H} 2$ ) are omitted for clarity). 
rearrange to the final product 5 through transition state TS3 with a very low free-energy barrier of $0.5 \mathrm{kcal} \mathrm{mol}^{-1}$, which can be deemed as following path III in Scheme 4. On the other hand, IM1 can also undergo a reversible ligand exchange through TS3 to afford 7 and HBpin, which are $8.6 \mathrm{kcal} \mathrm{mol}^{-1}$ less stable than 5 in free energy. The reaction from 7 and HBpin to 5 through IM1 needs to overcome a free-energy barrier of $14.7 \mathrm{kcal} \mathrm{mol}^{-1}$, which is in good agreement with our experimental value $\left(15.9 \mathrm{kcal} \mathrm{mol}^{-1}\right)$. This pathway corresponds to path II in Scheme 4 . Therefore, these calculation results clearly show that the observation of the crossover experiment is not due to the existence of two $\mathrm{H}_{2}$ activation pathways. Instead, the observed crossover products originate from the ligand exchange of IM1 following the cleavage of the $\mathrm{H}-\mathrm{H}$ bond, and the percentage of crossover product in the crossover experiment is determined by the free-energy difference between TS3 and $\mathbf{T S}^{2}{ }^{\prime}$. The calculated $\Delta \Delta H^{\neq}$and $\Delta \Delta S^{\neq}$values between TS3 $^{\prime}$ and TS3 are $4.7 \mathrm{kcal} \mathrm{mol}^{-1}$ and $5.6 \mathrm{cal} \mathrm{mol}^{-1} \mathrm{~K}^{-1}$, respectively, and are in relatively good agreement with the experimental values. We also calculated the KIE value for this reaction and the computed value of 0.81 agrees very well with the measured KIE value.

To obtain insight into the $\mathrm{H}-\mathrm{H}$ bond activation process, NBO population analysis along the intrinsic reaction coordinate (IRC) was carried out. As shown in Fig. 4, the electron populations ${ }^{32}$ of both hydrogen atoms are quite similar throughout the whole process, clearly indicating that the $\mathrm{H}-\mathrm{H}$ bond is cleaved in a homolytic manner. During the process of coordination of $\mathrm{H}_{2}$ to $\mathbf{1}$ to form $\mathbf{1} \cdot \mathbf{H}_{2}$, the electron populations of the $\mathrm{H} 1$ and $\mathrm{H} 2$ atoms decrease by 0.26 and 0.28 e, respectively. NBO occupation analysis revealed that these population changes are mainly due to the charge transfer from the $\mathrm{H}-\mathrm{H} \sigma$ bond orbital to the empty p orbital of the B1 atom; the loss of the occupancy of the $\mathrm{H}-\mathrm{H} \sigma$ bond orbital ( 0.60 e) matches very well with the increase of the occupancy of the p orbital of the B1 atom (0.62 e). This charge transfer results in an increase of the population of the B1 atom by $0.75 \mathrm{e}$, which induces polarization of the $\mathrm{B}-\mathrm{B} \sigma$ bond towards the $\mathrm{B} 1$ atom and a decrease of the population of the $\mathrm{B} 2$ atom by $0.16 \mathrm{e}$. The contribution from the

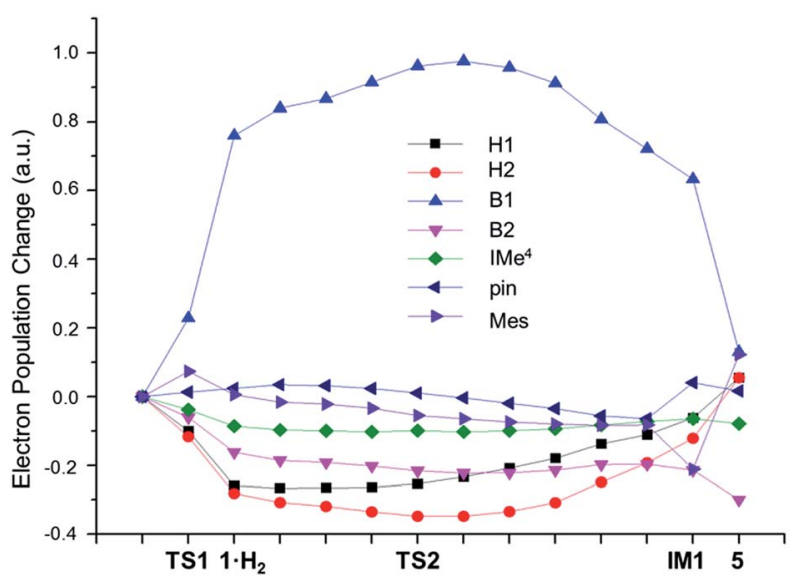

Fig. 4 Electron population change along the IRC of the reaction between 1 and $\mathrm{H}_{2}$. atomic orbitals of B1 to the B-B $\sigma$ bonding orbital also increases from $52 \%$ in $\mathbf{1}$ to $59 \%$ in $\mathbf{1} \cdot \mathbf{H}_{\mathbf{2}}$. Such polarization is even larger than a known boryltitanium complex in which the boron atom contributes $54 \%$ of the Ti-B bond. ${ }^{33}$ This polarization of the B-B bond is in sharp contrast with the well-studied Lewis base coordinated $\mathrm{B}_{2} \operatorname{pin}_{2}$ complexes in which the B-B bond is polarized to the $\mathrm{sp}^{2}$ boron atom. ${ }^{33 b, 34}$ The $\mathrm{IMe}_{4}$ and mesityl ligands of the B1 atom in $\mathbf{1}$ are likely responsible for this counter-intuitive observation. Unlike the pinacol ligand, which can be an efficient electron-withdrawing group at an $\mathrm{sp}^{3}$ hybridized $\mathrm{B}$ atom, ${ }^{33 b, 34 b}$ neither $\mathrm{IMe}_{4}$ nor Mes can effectively draw electron density from the $\mathrm{B} 1$ atom when it receives electron charge from $\mathrm{H}_{2}$.

As the reaction proceeds from $\mathbf{1} \cdot \mathbf{H}_{\mathbf{2}}$ to TS2, the $\mathrm{H}-\mathrm{H} \sigma^{*}$ orbital gains $0.20 \mathrm{e}$, accompanied with a loss of $0.17 \mathrm{e}$ from the $\mathrm{B}-\mathrm{B} \sigma$ orbital, which is consistent with a charge transfer from the $\mathrm{B}-\mathrm{B} \sigma$ orbital to the $\mathrm{H}-\mathrm{H} \sigma^{*}$ orbital. Due to the polarization of the B-B $\sigma$ bond (the contribution from the atomic orbitals of $\mathrm{B} 1$ is $60 \%$ ), this charge transfer predominately originates from the $\mathrm{B} 1 \mathrm{atom}$. The back donation from the $\mathrm{B} 1 \mathrm{atom}$, combined with the concomitant charge transfer from the $\mathrm{H}-\mathrm{H} \sigma$ bond orbital to the empty p orbital of the B1 atom, ensures that both $\mathrm{H}$ atoms strongly coordinate to the $\mathrm{B} 1$ atom (the bond orders of B1-H1 and B1-H2 are 0.64 and 0.54 respectively). Furthermore, the polarization of the $\mathrm{B}-\mathrm{B}$ bond results in an increase of positive charge on the Bpin moiety in TS2 $(q=0.21)$ compared to $1(q=0.04)$, which induces the migration of the electron-rich mesityl group from the B1 to B2 atom to form a B-C-B 3c2e bond in IM1.

\section{Conclusions}

In this work we have reported the synthesis of an NHCcoordinated borylborenium complex (1). When this borylborenium complex was treated with $\mathrm{H}_{2}$, addition of $\mathrm{H}_{2}$ to the borenium center was observed along with elimination of mesityl and Bpin substituents. The mechanistic studies revealed an unprecedented concurrent addition/elimination process in which polarization of the $\mathrm{B}-\mathrm{B}$ bond upon coordination of $\mathrm{H}_{2}$ plays a critical role. Our discovery advances the understanding of dihydrogen activation involving high valent species, and may offer a new pathway for the activation of a broader range of element-element bonds.

\section{Conflicts of interest}

There are no conflicts to declare.

\section{Acknowledgements}

Financial support from the National Natural Science Foundation of China $(21372048,21573044,21672039)$ and the Shanghai Science and Technology Committee (16DZ2270100) is gratefully acknowledged. We also thank the High Performance Computer Center of Fudan University for the allocation of computing time. We thank Dr Yue-Jian Lin for their help in the crystallography study. 


\section{Notes and references}

1 G. J. Kubas, Chem. Rev., 2007, 107, 4152-4205.

2 J. G. de Vries and C. J. Elsevier, The Handbook of Homogeneous Hydrogenation, Wiley-VCH, Weinheim, 2007.

3 G. D. Frey, V. Lavallo, B. Donnadieu, W. W. Schoeller and G. Bertrand, Science, 2007, 316, 439-441.

4 A. V. Protchenko, K. H. Birjkumar, D. Dange, A. D. Schwarz, D. Vidovic, C. Jones, N. Kaltsoyannis, P. Mountford and S. Aldridge, J. Am. Chem. Soc., 2012, 134, 6500-6503.

5 T. Chu, I. Korobkov and G. I. Nikonov, J. Am. Chem. Soc., 2014, 136, 9195-9202.

6 R. Waterman, Organometallics, 2013, 32, 7249-7263.

7 R. Noyori and T. Ohkuma, Angew. Chem., Int. Ed., 2001, 40, 40-73.

8 (a) G. C. Welch, R. R. S. Juan, J. D. Masuda and D. W. Stephan, Science, 2006, 314, 1124-1126; (b) D. W. Stephan and G. Erker, Angew. Chem., Int. Ed., 2010, 49, 46-76; (c) D. W. Stephan and G. Erker, Angew. Chem., Int. Ed., 2015, 54, 6400-6441; (d) D. W. Stephan, J. Am. Chem. Soc., 2015, 137, 10018-10032.

9 Addition of covalent bonded species, such as $\mathrm{Cl}_{2}$, to high valent metal complexes with non-innocent supporting ligands is known, see: K. J. Blackmore, J. W. Ziller and A. F. Heyduk, Inorg. Chem., 2005, 44, 5559-5561.

10 Z. Lu, Z. Cheng, Z. Chen, L. Weng, Z. H. Li and H. Wang, Angew. Chem., Int. Ed., 2011, 50, 12227-12231.

11 G. I. Nikonov, S. F. Vyboishchikov and O. G. Shirobokov, J. Am. Chem. Soc., 2012, 134, 5488-5491.

12 (a) M. Devillard, R. Brousses, K. Miqueu, G. Bouhadir and D. Bourissou, Angew. Chem., Int. Ed., 2015, 54, 5722-5726; (b) M. Devillard, S. Mallet-Ladeira, G. Bouhadir and D. Bourissou, Chem. Commun., 2016, 52, 8877-8880.

13 For examples of the activation of $\mathrm{H}_{2}$ with borenium complexes in the presence of bases, see: (a) J. M. Farrell, J. A. Hatnean and D. W. Stephan, J. Am. Chem. Soc., 2012, 134, 15728-15731; (b) E. R. Clark, A. Del Grosso and M. J. Ingleson, Chem.-Eur. J., 2013, 19, 2462-2466; (c) P. Eisenberger, B. P. Bestvater, E. C. Keske and C. M. Crudden, Angew. Chem., Int. Ed., 2015, 54, 2467-2471.

14 Y. Wang, W. Chen, Z. Lu, Z. H. Li and H. Wang, Angew. Chem., Int. Ed., 2013, 52, 7496-7499.

15 D. P. Curran, A. Solovyev, M. M. Brahmi, L. Fensterbank, M. Malacria and E. Lacôte, Angew. Chem., Int. Ed., 2011, 50, 10294-10317.

16 For examples of borylboreniums see: (a) H. Braunschweig, A. Damme, R. D. Dewhurst, T. Kramer, T. Kupfer, K. Radacki, E. Siedler, A. Trumpp, K. Wagner and C. Werner, J. Am. Chem. Soc., 2013, 135, 8702-8707; (b) A. Prokofjevs, Angew. Chem., Int. Ed., 2015, 54, 13401-13405.

17 A. Solovyev, Q. Chu, S. J. Geib, L. Fensterbank, M. Malacria, E. Lacôte and D. P. Curran, J. Am. Chem. Soc., 2010, 132, 15072-15080.
18 D. S. Laitat, P. Müller and J. P. Sadighi, J. Am. Chem. Soc., 2005, 127, 17196-17197.

19 (a) C. Fan, L. G. Mercier, W. E. Piers, H. M. Tuononen and M. Parvez, J. Am. Chem. Soc., 2010, 132, 9604-9606; (b) A. Y. Houghton, V. A. Karttunen, C. Fan, W. E. Piers and H. M. Tuononen, J. Am. Chem. Soc., 2013, 135, 941-947.

20 In the presence of Lewis bases, organoboranes are known to activate $\mathrm{H}_{2}$ even at $-78{ }^{\circ} \mathrm{C}$, for examples see $(a)$ D. Holschumacher, T. Bannenberg, C. G. Hrib, P. G. Jones and M. Tamm, Angew. Chem., Int. Ed., 2008, 47, 7428-7432; (b) P. A. Chase and D. W. Stephan, Angew. Chem., Int. Ed., 2008, 47, 7433-7437; (c) L. Greb, P. Oňa-Burgos, B. Schirmer, S. Grimme, D. W. Stephan and J. Paradies, Angew. Chem., Int. Ed., 2012, 51, 10164-10168.

21 C. C. Caries and S. Guccione, Organometallics, 2008, 27, 747752.

22 A. Prokofjevs, J. W. Kampf, A. Solovyev, D. P. Curran and E. Vedejs, J. Am. Chem. Soc., 2013, 135, 15686-15689.

23 Observation of no H/D scrambling in Mes group eliminates the potential mechanism involving hydrogenolysis of $\mathrm{B}-\mathrm{C}$ bond and subsequent $\mathrm{C}-\mathrm{H}$ borylation.

24 For examples of heterolytic cleavage of $\mathrm{H}_{2}$ along B-E bonds see ref. 19 and S. J. Geier, T. M. Gilbert and D. W. Stephan, J. Am. Chem. Soc., 2008, 130, 12632-12633.

25 F. Dahcheh, D. Martin, D. W. Stephan and G. Bertrand, Angew. Chem., Int. Ed., 2014, 53, 13159-13163.

26 E. v. Grotthuss, M. Diefenbach, M. Bolte, H.-W. Lerner, M. C. Holthausen and M. Wagner, Angew. Chem., Int. Ed., 2016, 55, 14067-14071.

27 N. Tsukahara, H. Asakawa, K.-H. Lee, Z. Lin and M. Yamashita, J. Am. Chem. Soc., 2017, 139, 2593-2596.

28 B. E. Hauger, D. Gusev and K. G. Caulton, J. Am. Chem. Soc., 1994, 116, 208-214.

29 J. M. Camara and T. B. Rauchfuss, J. Am. Chem. Soc., 2011, 133, 8098-8101.

30 (a) Y. Zhao and D. G. Truhlar, J. Chem. Phys., 2006, 125, 194101-194118; (b) Y. Zhao and D. G. Truhlar, J. Phys. Chem. A, 2006, 110, 5121-5129.

31 A. Hübner, M. Diefenbach, M. Bolte, H.-W. Lerner, M. C. Holthausen and M. Wagner, Angew. Chem., Int. Ed., 2012, 51, 12514-12518.

32 Electron population of an atom is the total number of electrons on the atom. A positive value represents an increase of population relative to that of $\mathbf{1}$ and $\mathrm{H}_{2}$.

33 (a) T. Terabayashi, T. Kajiwara, M. Yamashita and K. Nozaki, J. Am. Chem. Soc., 2009, 131, 14162-14163; (b) J. Cid, J. J. Carbó and E. Fernández, Chem.-Eur. J., 2012, 18, 12794-12802.

34 (a) K.-s. Lee, A. R. Zhugralin and A. H. Hoveyda, J. Am. Chem. Soc., 2009, 131, 7253-7255; (b) A. Bonet, C. PubillUlldemolins, C. Bo, H. Gulyás and E. Fernández, Angew. Chem., Int. Ed., 2011, 50, 7158-7161. 